Perspective

\section{Know your numbers?}

\section{Perspective}

We all have heard the importance surrounding regular health check-ups to ensure things are running smoothly within our bodies. But how often does life get in the way and our own wellbeing get put on the backburner?.. At a recent biometric screening event, I witnessed just how imperative it was for a particular individual to participate. After becoming aware of several potential health conditions through the screening, this individual sought immediate medical attention that may have saved their life. It just goes to show, you never ultimately know what is transpiring within your body until you know your numbers.

This past week, I witnessed an incident that served as an eyeopening reminder at just how important it is to be proactive about your personal health and well-being.

The incident?. While attending a biometric screening event for a client of mine, a participant was given an immediate care referral form at the conclusion of their screening. The reasoning?. Off-the-chart cholesterol, blood pressure, and blood sugar levels...The individual, surprised and concerned with the results, was then taken to a local facility where they received immediate medical attention.

In the past, I have heard similar stories taking place at health screening events but this was my first time witnessing it for myself. And it definitely made an impact!

This type of incident, though concerning and eye-opening for all, is not rare. Many can go months and even years without knowing they have a significant health risk or condition.

Let's take the three health risks mentioned above for example:

High cholesterol- Over 73.5million adults in the U.S. have High LDL Cholesterol (Also known as the "Bad" cholesterol).

High blood pressure-About 1 in every 3 adults (70million Americans) suffers from Hypertension.

Diabetes (High blood glucose) - Over 29million Americans have Diabetes (Type I or Type II).

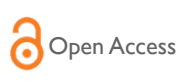

CrossMark
Volume 2 Issue 5 - 2015

Matt Heidenfelder
MPH, Lewis University, USA

Correspondence: Matt Heidenfelder, MPH, Lewis University, USA, Tel 8478095259, Email mattheidenfelder@yahoo.com

Received: May 19, 2015 | Published: September 08, 2015

How many do you think are unaware of having at least 1 of the 3 above conditions? It may be difficult to put an exact number on it but it is estimated that over 8million diabetics have not yet been diagnosed. Imagine what the number is for Cholesterol and Hypertension cases!

All three conditions listed above can be present without any symptoms for extended periods of time and can lead to serious health complications down the road. Fortunately, for the individual, the health risks were identified. Imagine if they weren't.

Getting screened in a health screening event or even by your physician is a great initial step in identifying your current health status. Though we can't control all life throws at us, much of our own well-being is in our hands. Let's take the action we need to ensure a healthy and happy life now and in the future. Get to know your numbers.

Source for statistics: CDC.gov

\title{
Acknowledgements
}

None.

\section{Conflict of interest}

The author declares no conflict of interest. 